\title{
The role of magnesium in the growth of calcite: An AFM study
}

\author{
J.M. Astilleros ${ }^{\text {a,* }}$, L. Fernández-Díaz ${ }^{a}$, A. Putnis ${ }^{\text {b }}$ \\ a Dpto. Cristalografia y Mineralogia, Facultad de CC. Geologicas, Universidad Complutense de Madrid, C/José Antonio Novais 2, Madrid 28040, Spain \\ b Institut für Mineralogie, Universitüt Münster, Corrensstrasse 24, D-48149, Gernany
}

Keywords:

Solid solution-aqueous solution

Atomic force microscopy

Crystal growth inhibition

Calcite

Magnesium

\begin{abstract}
A B S T R A C T
The mechanisms that determine the inhibition of calcite growth by magnesium have remained unclear and subject to controversy over decades. Although it has been long apparent that the inhibition mechanisms take place at the crystal-solution interface, the molecular phenomena occurring at calcite surfaces in contact with Mg-bearing solutions are still not completely understood. The main goal of this work is to contribute to further clarify those phenomena. With this aim, we carried out in situ atomic force microscopy (AFM) observations of the growth behaviour of calcite $\left\{\begin{array}{ll}10 & 14\end{array}\right\}$ surfaces in contact with supersaturated aqueous solutions $\left(\boldsymbol{\beta}=5\right.$ ) bearing different amounts of $\mathrm{Mg}$ (ranging from 0.05 to $4.00 \mathrm{mmoldm}^{3}$ ). Under the conditions considered, growth occurred by monolayer spreading. Our observations revealed that only the first elementary growth layer advancing on the original calcite surfaces grow normally, showing characteristics nearly identical to the growth of pure calcite. However, subsequent monolayers behave differently. Thus, as soon as one of these monolayers reaches areas of the surface that have grown incorporating $\mathrm{Mg}$ and whose composition can consequently be described as $\mathrm{Mg}_{\mathrm{x}} \mathrm{Ca}_{1-\mathrm{x}} \mathrm{CO}_{3}$, the rate at which this step advances significantly decreases. Moreover, the step becomes progressively rougher. A clear relationship between the extent of the inhibition effect and the concentration of $\mathrm{Mg}$ in the aqueous solution exists. Furthermore, our observations allow us to conclude that each newly formed monolayer exerts a certain control on the development of the growth of subsequent monolayers. Such a control causes the reproduction of the nanotopographic features of the original surface, producing the so called "template effect". This behaviour cannot be easily incorporated within the general framework of the currently accepted impurity crystal growth models, which are based on either the pinning of elementary step motion by impurities or changes in the solubility of the newly formed layers as a result of the incorporation of the impurity into the lattice of the growing crystal. We discuss our results on the basis of the solid solutionaqueous solution model and provide a complementary explanation for the development of "dead zones" in the case of the growth of calcite $\left\{\begin{array}{ll}10 & \overline{1} 4\end{array}\right\}$ surfaces from divalent cation-bearing aqueous solutions.
\end{abstract}

\section{Introduction}

The importance of $\mathrm{Mg}^{2+}$ in the geochemistry of calcium carbonate-water systems lies both in the similarity of its chemical properties to $\mathrm{Ca}^{2+}$ and its abundance (it is the most abundant divalent cation in seawater; the present $\mathrm{Mg} / \mathrm{Ca}$ ratio of seawater is $\sim 5.2 \mathrm{~mol} /$ $\mathrm{mol}$ ). As a result, in the last decades much effort has been focused on understanding the processes involved in the interaction between calcium carbonate minerals and magnesium in aquatic environments at earth surface conditions. Calcite crystals formed in marine environments usually contain significant amounts of magnesium. Moreover, the concentration of this element in calcium carbonate biominerals and calcite cements has global implications, since it is considered to be a reliable proxy for the composition and the temperature of palaeoseawaters (Chave, 1954a,b; Rosenthal et al., 1997; Stanley and Hardie, 1998; Stanley, 1999; Elderfield and Ganssen, 2000; Dickson, 2002; Bryan and Marchitto, 2008). Consequently, the importance of the different physicochemical factors (essentially temperature, growth rate, $\left[\mathrm{Mg}^{2+}\right] /\left[\mathrm{Ca}^{2+}\right]$ ratios, presence of foreign ions and polymers, $P_{c_{2}}$, saturation state of water, transport conditions) controlling the occurrence and composition of magnesian calcites has been extensively discussed by geochemists (e.g., Moberly, 1968; Broecker et al., 1979; Mackenzie et al., 1983; Mucci and Morse, 1983; Mucci, 1987; Burton and Walter, 1987; Hartley and Mucci, 1996; Wasylenki et al., 2005; Stephenson et al., 2008).

Many investigations have addressed the role of magnesium on different aspects of the $\mathrm{CaCO}_{3}$ crystallization process. There is a general agreement that the presence of magnesium in the aqueous solution has a strong inhibiting effect on the growth of calcite (Reddy and Nancollas, 1976; Reddy and Wang, 1980; Falini et al., 1994; Fernández-Díaz et al., 1996; Chen et al., 2006). However, different aspects of such an inhibition effect still need to be unravelled. 
In this work we present in situ AFM observations of calcite $\left\{\begin{array}{ll}10 & 14\end{array}\right\}$ surfaces growing from $\mathrm{Mg}$-bearing supersaturated aqueous solutions. The evolution of the measured step advancement velocities as a function of the concentration of magnesium in the aqueous solution is discussed considering the thermodynamics of solid solution-aqueous solution systems. Moreover, the fit of our observations within the framework of the two main impurity growth models (step pinning model and impurity incorporation model) is checked. Finally, we provide an explanation for the development of "dead zones", which is based on the restrictions that the underlying substrate imposes to the lateral spread of overgrowing layers ("template effect") (Astilleros, 2001; Astilleros et al., 2002; Astilleros et al., 2003a; Higgins and Hu, 2005) and how this relates to the current models of growth in the presence of impurities.

\section{Experimental procedure}

Experiments to study the influence of $\mathrm{Mg}^{2+}$ on the growth of calcite were made by in situ observations on calcite $\left\{\begin{array}{ll}10 & 14\end{array}\right\}$ surfaces during growth, using a Digital Multimode AFM, equipped with a fluid cell. Calcite surfaces used as substrates were obtained by cleaving optically clear Iceland Spar. Before each growth experiment, deionised water was passed over the crystal in order to clean surfaces, as well as to adjust the AFM parameters and determine the crystallographic directions on calcite $\left\{\begin{array}{ll}10 & \overline{1} 4\end{array}\right\}$ surfaces.

Aqueous solutions for promoting growth were prepared by mixing $\mathrm{Na}_{2} \mathrm{CO}_{3}, \mathrm{MgCl}_{2}$ and $\mathrm{CaCl}_{2}$ (SIGMA $99+\%$ ). The $\mathrm{pH}$ of the solutions $(10.05 \pm 0.05$ in all cases) was measured using a TESTO $230 \mathrm{pH}$-meter with a $\mathrm{pH}$-meter electrode (type $05 \mathrm{pH}$ ) calibrated using 7.00 and 10.00 buffers (Schott Geräte). Table 1 shows the composition of the solutions used. Solutions were injected at intervals of about $30 \mathrm{~s}$ between each AFM scan in order to maintain the same degree of supersaturation during the observation time. The activity coefficients for $\mathrm{Ca}^{2+}, \mathrm{Mg}^{2+}$ and $\mathrm{CO}_{3}^{2-}$ were computed by means of PHREEQC, (Parkhurst and Appelo, 2000). The aqueous speciation program used considered the following species: $\mathrm{H}^{+}, \mathrm{OH}^{-}, \mathrm{Ca}^{2+}, \mathrm{Mg}^{2+}, \mathrm{Cl}^{-}, \mathrm{Na}^{+}, \mathrm{CO}_{3}^{2-}$, $\mathrm{HCO}_{3}^{-}, \mathrm{CaOH}^{+}, \mathrm{MgOH}^{+}, \mathrm{NaOH}^{0}, \mathrm{CaCO}_{3}^{0}, \mathrm{MgCO}_{3}^{0}, \mathrm{NaCO}_{3}^{-}, \mathrm{CaHCO}_{3}^{+}$, $\mathrm{MgHCO}_{3}^{+}$and $\mathrm{NaHCO}_{3}^{0}$.

For all solutions the supersaturation with respect to calcite was kept constant $\left(\boldsymbol{\beta}_{\text {calci }}=5\right)$, where $\boldsymbol{\beta}$ is defined as $a\left(\mathrm{Ca}^{2+}\right) a\left(\mathrm{CO}_{3}^{2-}\right) / K_{\text {calcie. }}$. Here $a\left(\mathrm{Ca}^{2+}\right)$ and $a\left(\mathrm{CO}_{3}^{2-}\right)$ are the ion activities of $\mathrm{Ca}^{2+}$ and $\mathrm{CO}_{3}^{2-}$ in the aqueous solution, respectively, and $K_{\text {calcite }}=10^{-8.48}$ is the solubility product of calcite (Ball et al., 1981). The amount of $\mathrm{Mg}^{2+}$ in solution was increased in each experiment by increasing the concentration of $\mathrm{MgCl}_{2}$. In order to maintain the supersaturation at a constant value with respect to calcite, Ca concentrations in the solutions were adjusted. In all the experiments, the carbonate concentration was maintained constant. Experiments were conducted at $25^{\circ} \mathrm{C}$ and $1 \mathrm{~atm}$.

\section{AFM observations of the growing surfaces}

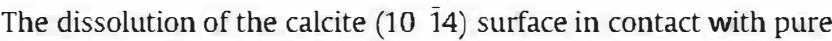
water is characterized by the formation and rapid coalescence of etch pits and by the retreat of the original cleavage steps. Fig. 1a shows the typical appearance of calcite $\left\{\begin{array}{ll}10 & 14\end{array}\right\}$ surface after some seconds in contact with deionized water. The etch pits show a typical rhombohedral shape, defined by the $\langle\overline{4} 41\rangle$ steps. The height of the steps is $3.1 \dot{A}$, which corresponds to the dimensions of a calcite unit cell. The retreat of the edges of these etch pits is highly anisotropic, with a pair of steps retreating rapidly ("positive steps" $[\overline{4} 41]_{+}$and $[48 \overline{1}]_{+}$) and the other one retreating very slowly ("negative steps"

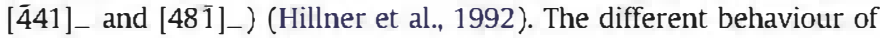
the steps allows one to determine the orientation of directions on the calcite surface. Once the cleavage surface was clean after being in contact with pure water, $\mathrm{Ca}^{2+}-\mathrm{Mg}^{2+}-\mathrm{CO}_{3}^{2-}$ solutions, whose compositions are described in Table 1, were injected into the fluid cell of the AFM. In all experiments, growth on the surface was observed. Fig. 1b-d show a representative sequence of AFM images of the growth process occurring on the calcite cleavage surface in contact with a supersaturated calcite aqueous solution $(\boldsymbol{\beta}=5)$, which contained $0.2 \mathrm{mmol} \mathrm{dm}^{-3}$ of $\mathrm{Mg}^{2+}$ (solution 2).As can be seen, during the whole sequence, growth occurs through the lateral advancement of steps. The advancement of these monomolecular steps leads to the filling of the original etch pits and the growth of monolayers on the calcite surface. A thorough examination of the images revealed that only the first elementary growth layers advancing on the original calcite surfaces grow normally. However, when these growth layers reach areas formed in contact with the solution containing $\mathrm{Mg}$, such as the filled-in etch pits, their velocities abruptly decrease and their advancement nearly stops. Small arrows in Fig. 1d indicate some examples of filled etch pits from whose edges growth slows down. The same growth behaviour pattern has been observed in all the experiments carried out in this system irrespective the concentration of $\mathrm{Mg}$ in the aqueous solution, although when this concentration was very low (solution 1), this effect was much less appreciable.

The strong inhibiting effect exerted by the newly formed substrate on the advancement of subsequent monolayers causes the reproduction of the original calcite microtopography. This is a common phenomenon, termed the "template effect", which up to now has been observed in a number of systems. In the particular case of calcite $\{10 \overline{14}\}$ surfaces growing from solutions containing impurities, this effect has been observed when growth occurred from aqueous solutions bearing manganese, strontium, cobalt or sulphate (Astilleros, 2001; Astilleros et al., 2002, 2003b; Freij et al., 2004; Vavouraki et al., 2008). Moreover, the same phenomenon has been also observed in experiments carried out on barite (001) surfaces growing from strontium, chromate or carbonate-bearing aqueous solutions (Astilleros et al., 2003a; Shtukenberg et al., 2005; Sánchez Pastor et al., 2006) and during the growth of dolomite (Higgins and Hu, 2005).

Fig. 2 shows a sequence obtained after injecting a supersaturated

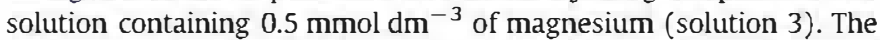
surface, rougher than in the previous case, is formed by a bunch of parallel steps spaced by a few nanometres, similar to those formed during spiral growth. After injecting the solution, all the steps begin to move forward. However, whereas step 1 always advances on the original surface, the rest of the steps immediately reach a surface formed as a result of the advancement of the previous steps, i.e. from a solution bearing $\mathrm{Mg}$. Identically to what was observed in the former

Table 1

Concentrations, $\mathrm{Mg}^{2+} / \mathrm{Ca}^{2+}$ ratio, $X_{\mathrm{Mg}^{2+}}$ 3,aq

\begin{tabular}{|c|c|c|c|c|c|c|}
\hline Solution no. & {$\left[\mathrm{CaCl}_{2}\right]\left(\mathrm{mmol} \mathrm{dm}^{-3}\right)$} & {$\left[\mathrm{MgCl}_{2}\right]\left(\mathrm{mmol} \mathrm{dm}^{-3}\right)$} & {$\left[\mathrm{Na}_{2} \mathrm{CO}_{3}\right]\left(\mathrm{mmol} \mathrm{dm}^{-3}\right)$} & $X_{\mathrm{Mg}^{2}+3, \mathrm{aq}}$ & {$\left[\mathrm{Mg}^{2+}\right] /\left[\mathrm{Ca}^{2+}\right]$ ratio } & Ionic strength \\
\hline 1 & 0.23 & 0.05 & 0.30 & 0.18 & 0.22 & $1.454 \times 10^{-3}$ \\
\hline 2 & 0.25 & 0.20 & 0.30 & 0.45 & 0.81 & $1.919 \times 10^{-3}$ \\
\hline 3 & 0.30 & 0.50 & 0.30 & 0.63 & 1.70 & $2.895 \times 10^{-3}$ \\
\hline 4 & 0.33 & 0.75 & 0.30 & 0.70 & 2.30 & $3.689 \times 10^{-3}$ \\
\hline 5 & 0.37 & 1.00 & 0.30 & 0.73 & 2.72 & $4.520 \times 10^{-3}$ \\
\hline 6 & 0.50 & 2.00 & 0.30 & 0.80 & 4.00 & $7.804 \times 10^{-3}$ \\
\hline 7 & 0.80 & 4.00 & 0.30 & 0.84 & 5.00 & $1.459 \times 10^{-2}$ \\
\hline
\end{tabular}



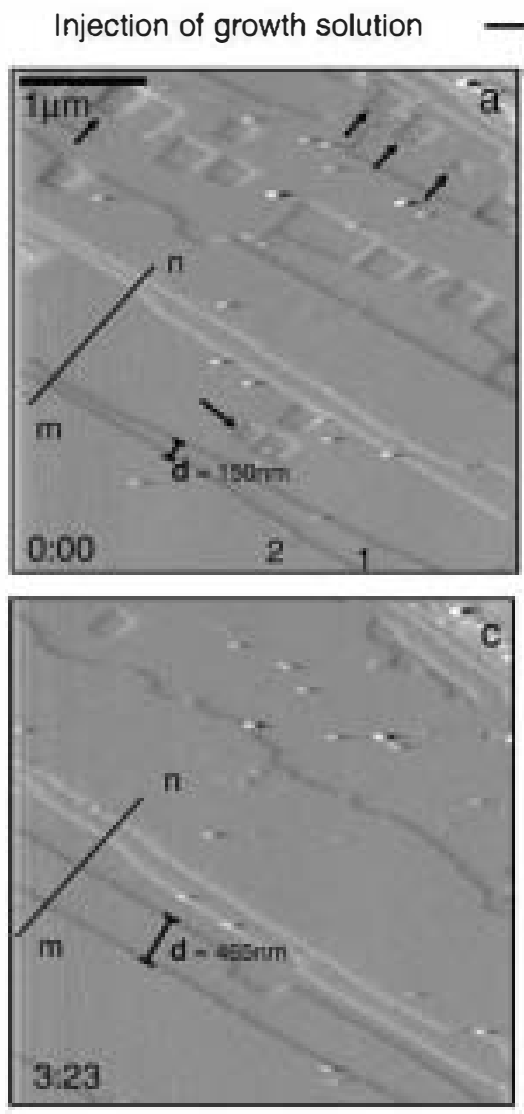
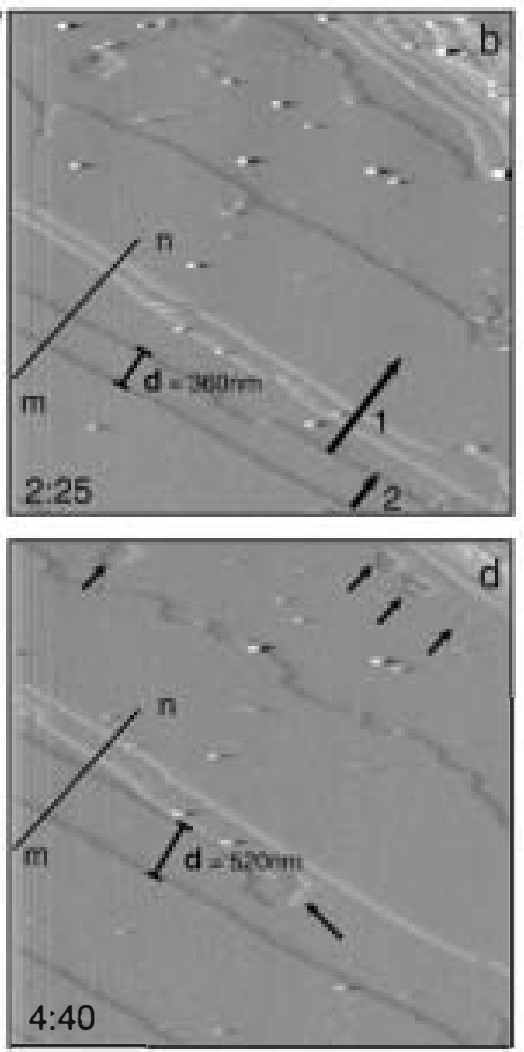

e

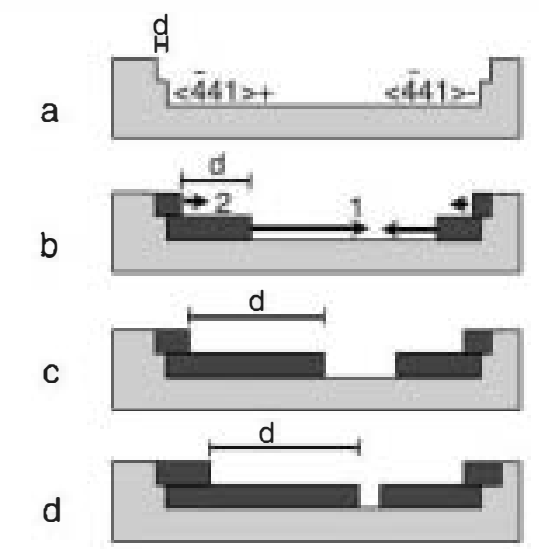

m $n$

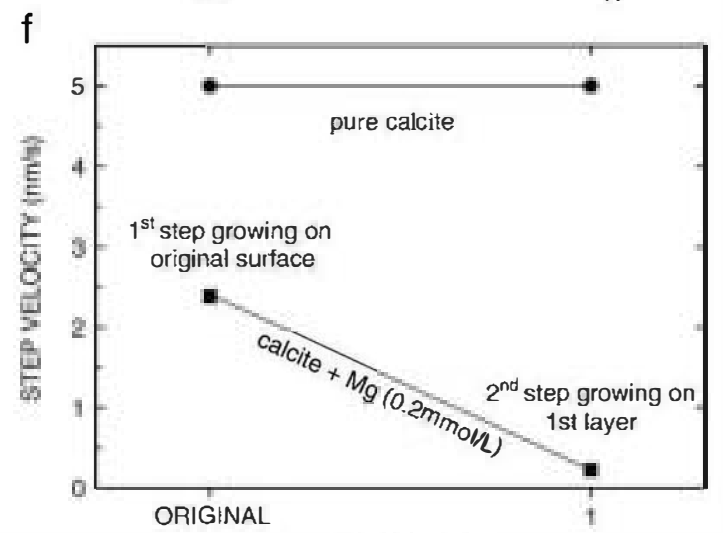

SUBSTRATE

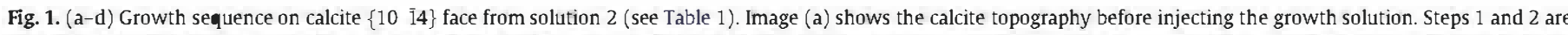

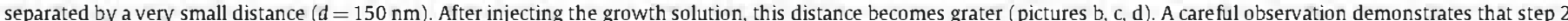

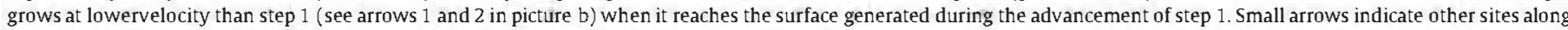

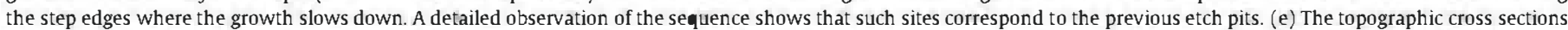

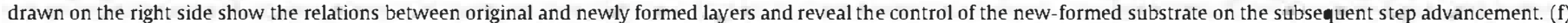

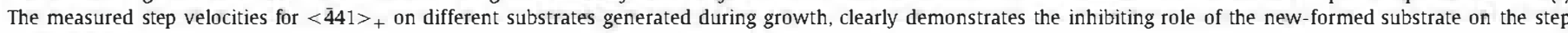
advancement.

case, the steps slow down. This divergence between the steps advancing on the original surface (pure calcite) and those advancing on a surface generated during growth from $\mathrm{Mg}$-bearing solution is clearly evidenced by the progressive increase of the distance, $d$, between step 1 and step 2 (Fig. $2 \mathrm{~d}$ and e). It is worth noting that this phenomenon could remain unnoticed if velocity measurements had only been taken on subsequent steps, where the separation between two consecutive steps is kept quite constant, but not considering the first step, which is the only one that grows on a substrate that has not formed from a solution containing Mg. Comparison of Fig. $2 \mathrm{a}$ and $\mathrm{c}$ demonstrates the faithful reproduction of the original surface. Arrows in Fig. 2c point out special features on the surface, where the "template effect" can be clearly observed.

Fig. 3 shows the velocity measurements of positive steps growing on the substrate generated during the experiments. When solution 1 (containing a very small amount of $\mathrm{Mg}\left(0.05 \mathrm{mmol} \mathrm{dm}^{-3}\right)$ ) was used, the velocity measurements only showed a slight difference between the steps advancing on the original pure-calcite substrate $\left(\sim 1 \mathrm{~nm} \mathrm{~s}^{-1}\right)$ and those advancing on the new substrate. In this case, the template effect is weakly exhibited. When solutions containing higher concentrations of $\mathrm{Mg}$ were used, the steps advanced very slowly (at velocities lower than $0.5 \mathrm{~nm} \mathrm{~s}^{-1}$ ) and the reproduction of the original surface was always observed. It is relevant that, although the step spreading rate was significantly reduced as a result of the presence of $\mathrm{Mg}$, a total stoppage of growth was not observed in any experiment.
Another interesting phenomenon which deserves special attention is the change of roughness of the step edges. Some minutes after injecting the supersaturated $\mathrm{Mg}$-bearing solution the edges of the growing steps, originally straight, become lobate. This transition from straight to rough edges has been previously observed by other authors (see for example Davis et al., 2000). From our observations, it can be concluded that this is a characteristic microtopographic feature of the steps advancing on calcite (10 14$)$ surface when in contact with a $\mathrm{Mg}$ bearing solution, which becomes more evident when the concentration of this ion in the solution is higher (solutions 3-7). Moreover, a most significant fact is that the steps only become lobate when their advancement occurs on a substrate formed in contact with the Mgbearing solution, but not on the original substrate. Fig. 4 shows an example of the effect of the substrate on both the step advancement velocity (template effect) and the roughness of the step edges. In this case, the amount of magnesium in the solution was higher than in the previous examples (solution 4). Fig. 4a shows the nanotopographic features of the calcite surface after some seconds in contact with water. After the injection of the growth solution, the monomolecular steps start to advance (Fig. 4b). During the first stages, while all the steps were growing on a pure-calcite substrate, no change in their roughness was observed: they remained basically straight. However, as soon as a step reached an area formed during the experiment from the solution containing $\mathrm{Mg}$, it became progressively rougher. Such an effect can be clearly observed by comparing the evolution of the 

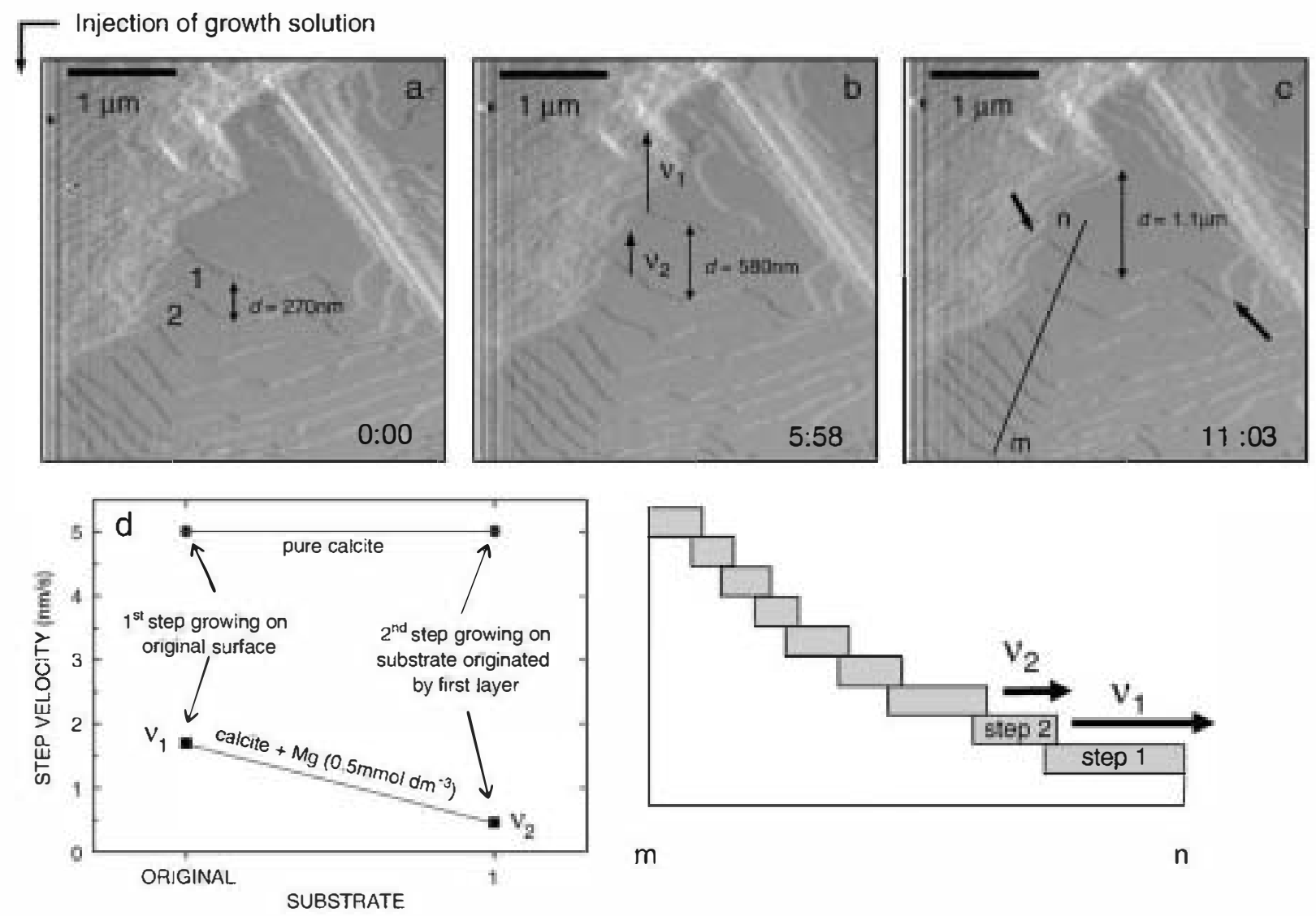

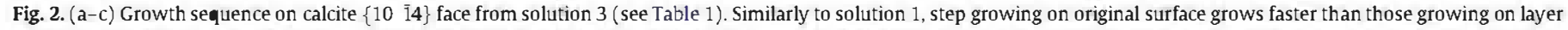

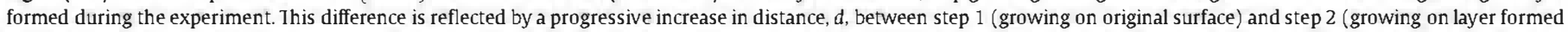

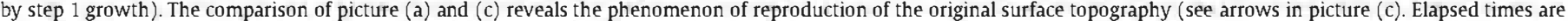

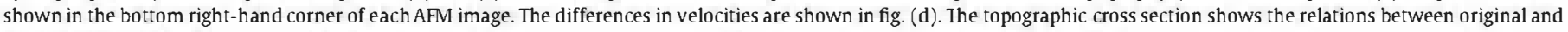
new-formed layers (e).

roughness of steps 2 and 3 while they were still growing on the original surface (Fig. 4b) and after they reached the new substrate generated as a result of the advancement of steps 1 and 2, respectively (Fig. 4c-f). In contrast, step 1 grew on the original substrate and remained straight, except in the areas marked with a straight line in Fig. 4c, where it grew on newly-filled etch pits. These observations suggest a clear relationship between the transition from straight to rough steps and the decrease in their velocity. Thus, the steps which

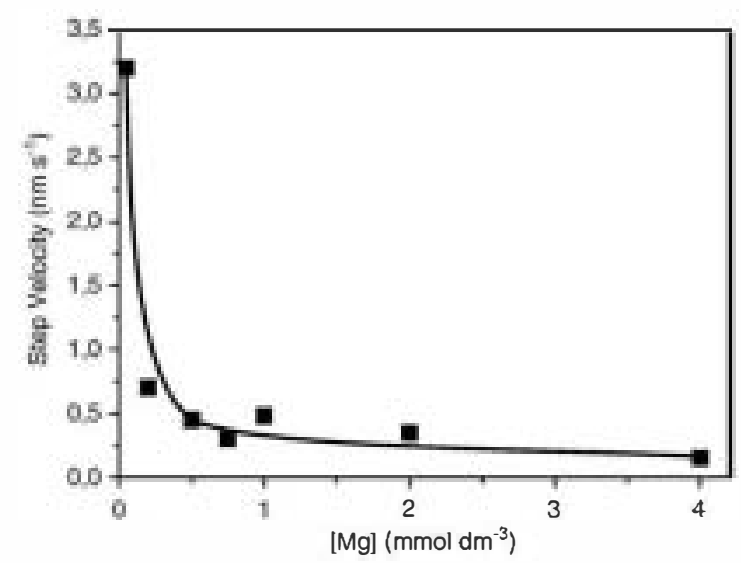

Fig. 3. Velocity measurements of positive steps advancing on the ( $\mathrm{Mg}, \mathrm{Ca}) \mathrm{CO}_{3}$-substrate. Although the steps advance very slowly (except for solution 1 ), no total step stoppage was observed in any experiment. become rougher grow more slowly (note the progressive increase of distance between steps 1 and 2).

\section{Discussion}

The effect of $\mathrm{Mg}^{2+}$ on the characteristics of the growth of monolayers on calcite $\left\{\begin{array}{ll}10 & \overline{1} 4\end{array}\right\}$ surface at a molecular scale has been hitherto explained by considering the two basic impurity models, the step pinning model (Cabrera and Vermilyea, 1958; Kubota and Mullin, 1995; van Enckevort et al., 1996; De Yoreo and Vekilov, 2003) and the impurity incorporation model (Berner, 1975; Davis et al., 2000; De Yoreo and Velilov, 2003). Explanations based on the step pinning model assume that the adsorption of hydrated $\mathrm{Mg}^{2+}$ at kink sites on step edges or at sites on terraces (Reddy and Wang, 1980; Mucci and Morse, 1983; Dove and Hochella, 1993; Gutjahr et al, 1996) causes the pinning of the steps as the growth monolayers spread on the surface. As a result, the step advancement is hindered. This could lead to the entry into the "deadzone", with the complete stoppage of step advancement, when the concentration of $\mathrm{Mg}^{2+}$ in the aqueous solution is very high. The amount of impurities necessary to cause a "dead-zone" increases with supersaturation and, as impurity adsorption is a reversible process, an increase of supersaturation can cause the removal of the adsorbed impurities, determining that steps grow again at the velocity corresponding to a pure solid at that supersaturation. The step pinning model has been proposed to explain the effect of several impurities on calcite growth by various authors (Teng et al., 1999; Astilleros et al., 2000).

Explanations based on the impurity incorporation model assume that $\mathrm{Mg}^{2+}$ incorporates into the calcite structure, forming a solid solution, which is considered to be more soluble than the pure phase. 

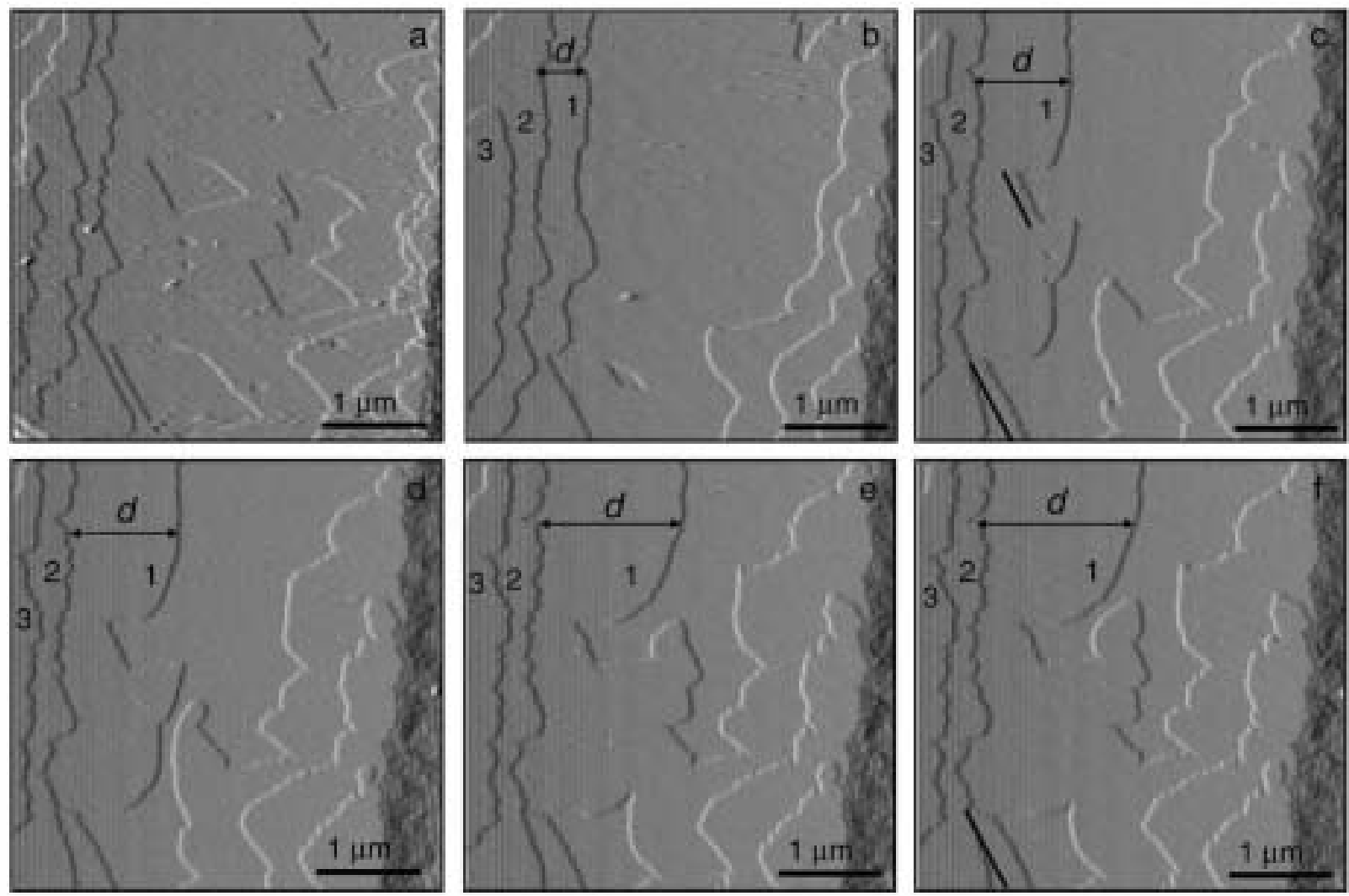

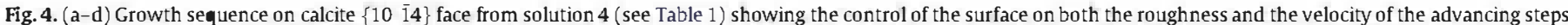

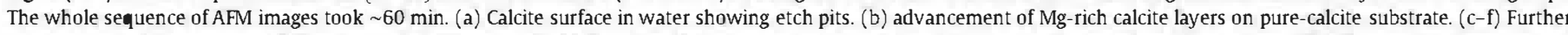

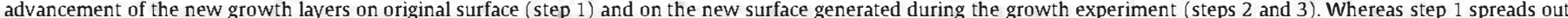

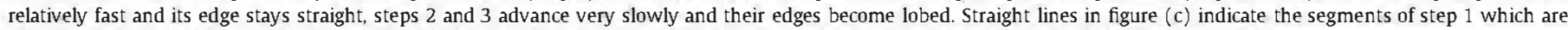
growing on filled etch pits. Comparison of images (a) and (f) reveals the phenomenon of reproduction of the original surface microtopography

It is then argued that the effective supersaturation of the aqueous solution for a monolayer with such a composition will be lower and, consequently, the step will advance at a slower rate. In this approach, just as in the step pinning model, there is a direct relationship between the amount of $\mathrm{Mg}^{2+}$ in the growth solution and the step advancement velocity. This relationship relies on the correlation between the concentration of $\mathrm{Mg}^{2+}$ in the aqueous solution and the amount of $\mathrm{Mg}^{2+}$ that incorporates into the calcite lattice and, consequently, in the increase in the solubility of the advancing layers. A major difference between the two approaches described is that, while in the case of the step pinning model the adsorption of impurities is a reversible process, in the impurity incorporation model the impurities incorporated within the crystal structure cannot be released back to the solution. As a result, the impurity incorporation model predicts that an increase in supersaturation will not result in the step velocity reverting to that corresponding to the growth of the pure phase.

The results of the atomic force microscopy experiments carried out by Davis et al. (2000) and Stephenson et al. (2008) seem to indicate that the characteristics of the inhibition of the growth on calcite $\left\{10 \overline{1} 4\right.$ \} surface by $\mathrm{Mg}^{2+}$ are in agreement with the impurity incorporation mechanism. These authors conclude that the incorporation of $\mathrm{Mg}^{2+}$ into calcite monolayers causes an increase in the free energy of the crystal. As a consequence, the solubility of these monolayers will also increase.

The AFM observations presented here can help to complete the picture of the calcite growth inhibition by magnesium and define an alternative explanation for the development of "dead zones". Although in none of our experiments a complete inhibition of the step advancement has been observed, in the case of solution with the higher $\mathrm{Mg} / \mathrm{Ca}$ ratio (solution 7) growth nearly stopped.
As described above, the first monolayer that spreads on the calcite surface has a slightly retarded growth relative to pure calcite. This retardation may be due to specific kinetic problems operating in this system, such as the very high enthalpy of hydration of $\mathrm{Mg}^{2+}$ (Lippmann, 1973; Mucci and Morse, 1983; Arvidson and Mackenzie, 2000). This explanation is clearly related to the very slow growth observed in magnesite $\left(\mathrm{MgCO}_{3}\right)$ and the difficulties related to the formation of dolomite $\left(\mathrm{MgCa}\left(\mathrm{CO}_{3}\right)_{2}\right)$ at $25^{\circ} \mathrm{C}$ and $1 \mathrm{~atm}$. From energetic calculations, Lippmann (1973) stated that calcite should crystallize about $10^{10}$ times faster than magnesite at $25^{\circ} \mathrm{C}$. However, the significant inhibition does not affect to the first monolayer but subsequent monolayers, for which the effectiveness of the inhibition almost exclusively relates to the characteristics of the new substrate generated during the experiment. According to our results, steps in contact with aqueous solution with identical composition can advance with different velocities depending on whether they grow on the original substrate or on the substrate generated during the experiments, in which case their velocity is drastically reduced. Such behaviour seems to indicate that the growth of the first monolayer on the original substrate produces a new surface with modified properties, most likely due to compositional differences with respect to the initial surface and the resultant lattice misfits.

It is apparent that the step pinning or the incorporation model described above cannot satisfactorily explain our results. It is worth noting that the general acceptance of the classical impurity models is based on macroscopic measurements. However, bulk experiments cannot provide a precise description of the retardation of elementary steps during growth and consequently can miss the nanoscopic phenomena described above. An accurate picture of processes taking place at the crystal-solution interface needs to incorporate the information provided by nanometric techniques such as AFM. 
Furthermore, from step velocity measurements carried out on preexisting growth spirals (Davis et al., 2000), where step edges remain equidistant, it is difficult to discern the effect of the newly formed layer and the step retardation can, therefore, be easily ascribed to other impurity models.

The growth behaviour of a crystal depends to a large extent on the supersaturation. In SS-AS systems, this parameter is not only determined by the solubility of the growing phase, but mainly by the composition (activity fractions) of the aqueous solution. From a thermodynamic point of view, it does not follow that an increase in solubility of the solid phase due to the incorporation of foreign ions results in a decrease of the effective supersaturation of the growth solution. In fact, an aqueous solution can be undersaturated with respect to a pure phase and supersaturated with respect to a more soluble solid solution composition (Tesoriero and Pankow, 1996; Astilleros et al., 2003c; Prieto et al., 2007). This thermodynamic argument is implicit in the concept of the equilibrium distribution coefficient and, therefore, in any representation of the thermodynamic equilibrium in SS-AS systems such as lippmann diagrams or Roozeboom-like plots. This point can be illustrated graphically. Fig. 5 shows the Lippmann diagram of the $(\mathrm{Ca}, \mathrm{Mg}) \mathrm{CO}_{3}-\mathrm{H}_{2} \mathrm{O}$ system at $25^{\circ} \mathrm{C}$, drawn using the distribution coefficient measurements obtained by Mucci and Morse (1983) from precipitation studies (Königsberger and Gamsjäger, 1992). An extensive explanation of Lippmann diagrams can be found in Glynn and Reardon (1990) and Prieto (2009). The diagram in Fig. 5 also shows the projection of the different aqueous solution compositions used in our experiments (dots 1-7). The length of vertical lines drawn from the depicted aqueous solution to solutus curves is directly proportional to the supersaturation of such aqueous solutions with respect to certain solid solutions. The compositions of such solid solutions are those which are at equilibrium with respect to an aqueous solution having the same activity fraction as the given aqueous solutions (for example, the solid $5^{\prime \prime}$ is at equilibrium with the aqueous solution $5^{\prime}$, which has the same activity fraction as aqueous solution 5 ). The supersaturation of such aqueous solutions with respect to the pure end member calcite ( $\boldsymbol{\beta}_{\text {calcite }}=5$, in every case) is lower, since the curve $\Sigma \Pi_{\text {calcite }}$ is always slightly above the solutus curve. Therefore, the impurity incorporation model cannot account for the reduction of velocity of step advancement since there is no actual decrease in supersaturation.

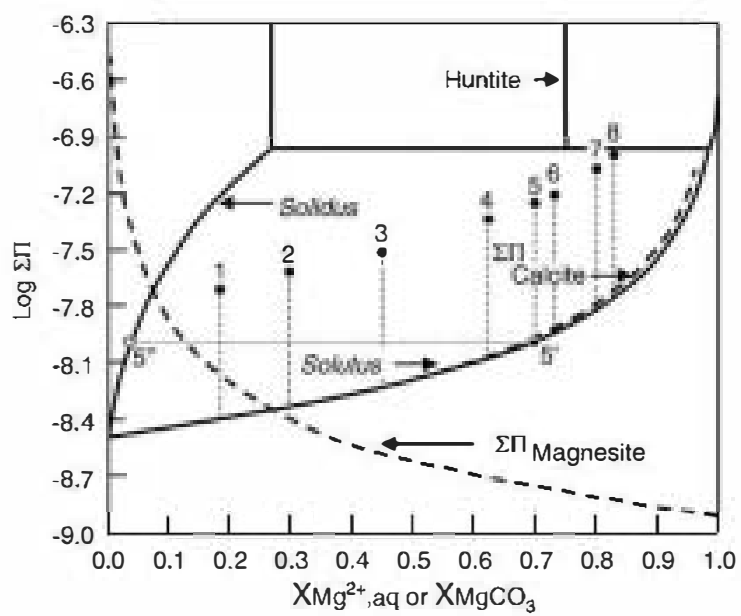

Fig. 5. Projection of the aqueous solutions used in the experiments on the pseudoequilibrium Lippmann diagram of the $(\mathrm{Ca}, \mathrm{Mg}) \mathrm{CO}_{3}-\mathrm{H}_{2} \mathrm{O}$ system (Königsberger and Gamsjäger, 1992). The length of the lines which link the depicted aqueous solutions with: a) the solutus curve, and b) the $\Sigma I I_{\text {calcite-curve is proportional to the }}$ supersaturation of such aqueous solutions with respect to a) certain solids at equilibrium with an aqueous phase having the same activity fraction as the given aqueous solutions, and b) the pure endmember calcite $\left(\boldsymbol{\beta}_{\text {calcir }}=5\right)$. Because the

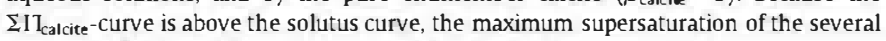
aqueous solutions will never correspond in any case, to pure calcite.
The main problem in applying the classical impurity models to our observations arises from the fact that the role played by the surface on the advancement of the steps is not taken into consideration in any of them. Moreover, according to these models any crystallographically equivalent step will advance at the same velocity when growing in contact with an aqueous solution with a specific composition. Understanding the mechanism by which the first monolayer controls the growth behaviour of the next layers causing retardation in step advancement is a challenging problem. Although a complete elucidation of this phenomenon is beyond the scope of this work, a tentative explanation of the process can be suggested. The formation of a solid solution always involves strain due to the different ionic radii and hence bond lengths of the substituted cations. Relaxation of the strain must be perpendicular to the layer, as would be expected for a monolayer growing epitaxially on a substrate. This relaxation will introduce local variations in the bond lengths and hence a local departure from the ideal topography, on an atomic scale, of the surface of the layer wherever the foreign cation is sited. Within this first layer the distribution of the "foreign" cations and hence local departures from an ideal atomically flat crystal surface may be random. In the next layer the distribution of foreign cations will no longer be random and will depend on the structure of the previous layer i.e. controlled by interactions between the ions. The effect of this control is to reduce the entropy of activation for the growth of this layer and hence also to decrease the step advancement rate and eventually, the suppression of step advancement. The fact that growth is significantly arrested at a "buried" step edge, reproducing the original topography (template effect), also suggests a dimensional difference, caused by changes in lattice parameters due to the formation of a mixed layer, between the new layers and the original steps, resulting in a "sub-nano step" at the original step edges. A similar argument has been proposed by Higgins and $\mathrm{Hu}$ (2005) to explain the reproduction of the underlaying nanotopography during the growth of $(\mathrm{Ca}, \mathrm{Mg}) \mathrm{CO}_{3}$ on dolomite $\left(\mathrm{CaMg}\left(\mathrm{CO}_{3}\right)_{2}\right)$ surface. Mapping of the surfaces using lateral force microscopy (LFM) showed an evident contrast of forces between the first $(\mathrm{Ca}, \mathrm{Mg}) \mathrm{CO}_{3}$ layer, directly grown on the dolomite substrate and the second layer, which spread on this first layer. These authors interpreted such a difference as resulting from the specific characteristics of the first layer, which is considered to be disordered and highly strained.

The template effect has also been observed in systems where a pure end member epitaxially grows on a substrate of the opposite end member of a solid solution (Shtukenberg et al., 2005; Pérez-Garrido et al., 2007, 2009). The growth characteristics described in such a specific case of growth in SS-AS systems, analogous to those observed in semiconductor and metal films growth, are usually explained using similar arguments. Moreover, the transition from straight to lobed or rough edges also seems to support a change in the flamess of the surface. On the flat faces of pure calcite, steps can grow without obstacles and, consequently their edges can remain straight. However, a change to atomically rougher surfaces containing impurities could prevent a uniform advancement of growing steps, causing, therefore, a transition to lobate edges.

\section{Conclusions}

Some conclusions on crystal growth from multicomponent aqueous solutions can be drawn from our observations:

a) In contrast to the growth of monolayers on a substrate of identical composition, when monolayers grow from a multicomponent solutions, with a composition that may differ from that of the substrate, a unique value for the rate of step advancement cannot be defined, even for specific supersaturation and foreign ion concentration values. The different velocities measured in the same experiment for successive monolayers indicate that step advancement behaviour is not a simple extension of that observed 
in pure substances. Consequently, the relationship between supersaturation/step advancement for pure systems cannot directly be applied to the growth of solids in presence of multicomponent aqueous solution.

b) The blocking of crystal growth and the ransition from straight to rough edges is a far more complex phenomenon than assumed from current impurity models. Much complexity arises from the strong influence exerted by the structure of the surfaces formed in the presence of impurities on the whole growth processes via strain relaxation

c) Our work indicates that the observation of the nanometric features of surfaces growing from multicomponent solutions provides important information to complete the picture of the influence of impurities on crystal growth and improve the currently accepted impurity models.

\section{Acknowledgements}

We are indebted to the Spanish Ministry of Science and Innovation (Project CGL2007-65523-C02-01) and the Comunidad de Madrid (Project CAM-2008 910148) for their partial support of this work. The AFM facilities in the Institut für Mineralogie, University of Münster are supported by the Deutsche Forschungsgemeinschaft (DFG).

\section{References}

Arvidson, RS., Mackenzie, F.T., 2000. Temperature dependence of mineral precipitation rates along the $\mathrm{CaCO}_{3}-\mathrm{MgCO}_{3}$ join. Aquatic Geochemistry 6, 249-256

Astilleros, J.M., 2001. Estudio integrado de la cristalización de soluciones sólidas no ideales: ( $\mathrm{Ca}, \mathrm{M}) \mathrm{CO}_{3}(\mathrm{M}=\mathrm{Ba}, \mathrm{Sr}, \mathrm{Mn})$. Ph.D. Thesis (in spanish). Universidad Complutense de Madrid (2001).

Astilleros, J.M., Pina, C.M., Fernández-Díaz, L, Putnis, A., 2000. The effect of barium on calcite $\{1014\}$ surfaces during growth. Geochimica et Cosmochimica Acta 64, 2965-2972.

Astilleros, J.M., Pina, C.M., Fernández-Díaz, L., Putnis, A., 2002. Molecular scale surface processes during the growth of calcite in the presence of manganese. Geochimica et Cosmochimica Acta 66, 3177-3189.

Astilleros, J.M., Pina, C.M., Fernández-Díaz, L., Putnis, A., 2003a. Nanoscale growth of solids crystallising from multicomponent aqueous solutions. Surface Science 545, L767-L773.

Astilleros,J.M., Pina, C.M., Fernández-Díaz, L, Putnis, A., 2003b. Metastable phenomena on calcite $\{1014\}$ surfaces growing from $\mathrm{Sr}^{2+}-\mathrm{Ca}^{2+}-\mathrm{CO}_{3}^{2-}$ aqueous solutions. Chemical Geology 193, 93-107.

Astilleros, J.M., Pina, C.M., Fernández-Díaz, L., Putnis, A., 2003c. Supersaturation functions in binary solid solution-aqueous solution systems. Geochimica et Cosmochimica Acta 67, 1601-1608.

Ball, J.W., Nordstrom, D.M., Jenne, E.A., 1981. Additional and revised thermochemical data and computer code for WATEQ2 - a computerized chemical model for trace and major element speciation and mineral equilibria of natural waters. WRI 78116. US Geological Survey. Menlo Park, CA.

Berner, R.A., 1975. The role of magnesium in the crystalgrowth of calcite and aragonite from seawater. Geochimica et Cosmochimica Acta 39, 489-504.

Broecker, W.S., Takahashi, T., Simpson, H.J., Peng, T.H., 1979. Fate of fossil fuel carbon dioxide and the global carbon cycle. Science 206, 409.

Bryan, S.P., Marchitto, T.M., 2008. Mg/Ca-temperature proxy in benthic foraminifera: new calibrations from the Florida Straits and a hypothesis regarding $\mathrm{Mg} / \mathrm{Li}$ Paleoceanography 23, PA220.

Burton, E.A., Walter, L.M., 1987. Relative precipitation rates of aragonite and $\mathrm{Mg}$ calcite from seawater: temperature or carbonate ion control? Geology 15, 111-114.

Cabrera, N., Vermilyea, D A., 1958. The growth of crystals from solution. In: Doremus, R.H., Roberts, B.W., Turnbull, D. (Eds.), Growth and Perfection of Crystals. Chapman \& Hall, pp. $393-410$

Chave, K.E., 1954a. Aspects of the biochemistry of magnesium 1. Calcareous and marine organisms. Journal of Geology 62, 266-283.

Chave, K.E., 1954b. Aspects of the biochemistry of magnesium 2. Calcareous sediments and rocks. Journal of Geology 62, 587-599.

Chen, T., Neville, A., Yuan, M., 2006. Influence of $\mathrm{Mg}^{2+}$ on $\mathrm{CaCO}_{3}$ formation - bulk precipitation and surface deposition. Chemical Engineering Science 61, 5318-5327.

Davis, K.J., Dove, P.M., De Yoreo, J.J., 2000. The role of $\mathrm{Mg}^{2+}$ as an impurity in calcite growth. Science 290, 1134-1137.

De Yoreo, J.J., Vekilov, P.G., 2003. Principles of crystal nucleation and growth. In: Biomineralization. Reviews in Mineralogy \& Geochemistry 54, 57-93.

Dickson, J.A.D., 2002. Fossil echinoderms as monitor of the $\mathrm{Mg} / \mathrm{Ca}$ ratio of phanerozoic oceans. Science $298,1222-1224$.

Dove, P.M., HochellaJr., M.F., 1993. Calcite precipitation mechanisms and inhibition by orthophosphate: in situ observations by scanning force microscopy. Geochimica et Cosmochimica Acta 57, 705-714.

Elderfield, H., Ganssen, G., 2000. Past temperature and $\mathbf{~}^{\mathbf{1 2}} \mathrm{O}$ of surface ocean waters inferred from foraminiferal $\mathrm{Mg} / \mathrm{Ca}$ ratios. Nature $405,442-445$.
Falini, G., Gazzano, M., Ripamonti, A., 1994 Crystallization of calcium carbonate in presence of magnesium and polyelectrolytes. Journal of Crystal Growth 137, 577-584.

Fernández-Díaz, L., Putnis, A., Prieto, M., Putnis, C.V., 1996. The role of magnesium in the crystallization of calcite and aragonite in a porous medium. Journal of Sedimentary Research 66, 482-491.

Freij, S.J., Putnis, A., Astilleros, J.M., 2004. Nanoscale observations of the effect of cobalt on calcite growth and dissolution. Journal of Crystal Growth 267, 288-300.

Glynn, P.D., Reardon, E.J., 1990. Solid-solution aqueous-solution equilibria: thermodynamic theory and representation. American Journal of Science 290, 164-201.

Gutjahr, A., Dabringhaus, H., Lacmann, R., 1996. Studies of the growth and dissolution linetics of the $\mathrm{CaCO}_{3}$ polymorphs calcite and aragonite. II. The influence of divalent cation additives on the growth and dissolution rates. Journal of Crystal Growth 158, 310-315

Hartley, G., Mucci, A., 1996. The influence of $\boldsymbol{P}_{\mathrm{Ce}_{2}}$ on the partitioning of magnesium in calcite overgrowths precipitated from artificial seawater at $25^{\circ} \mathrm{C}$ and $1 \mathrm{~atm}$ total pressure. Geochimica et Cosmochimica Acta 60,315-324.

Higgins, S.R, Hu, X, 2005. Self limiting growth on dolomite: experimental observations with in situ atomic force microsøpy. Geochimica et Cosmochimica Acta 69, 2085-2094

Hillner, P.E., Gratz, A.J., Manne, S., Hansma, P.K., 1992. Atomic-scale imaging of calcite growth and dissolution in real time. Geology 20, 359-362

Königsberger, E., Gamsjäger, H., 1992. Solid-solute phase equilibria in aqueous solution. VII: a re-interpretation of magnesian calcite stabilities. Geochimica et Cosmochimica Acta 56, 4095-4098.

Kubota, N., Mullin, J.W., 1995. A kinetic model for crystal growth from aqueous solution in the presence of impurity. Journal of Crystal Growth 152, 203-208.

Lippmann, F., 1973. Sedimentary Carbonate Minerals. Springer-Verlag, p. 228.

Mackenzie, F.T., Bischoff, W.D., Bishop, C., Ioijens, M., Schoomaker, J., Wollast, R, 1983 Magnesian calcites: low temperature occurrence and solid-solution behaviour Carbonates: Mineralogy and Chemistry: Reviews in Mineralogy, vol. 11, pp. 97-144.

Moberly, R., 1968. Composition of magnesiam calcites of algae and pelecypods by electron microprobe analysis. Sedimentology 11, 61-82.

Mucci, A., 1987. Influence of temperature on the composition of magnesian calcite overgrowths precipitated from seawater. Geochimica et Cosmochimica Acta 51, $1977-1984$.

Mucci, A., Morse, J.W., 1983. The incorporation of $\mathrm{Mg}^{2+}$ and $\mathrm{Sr}^{2+}$ into calcite overgrowths. Geochimica et Cosmochimica Acta 47, 217-233.

Parkhurst, D.L., Appelo, C.A.J., 2000. User's guide to PHREEQC (version 2) - a computer program for speciation, batch-reaction, one-dimensional transport, and inverse geochemical calculations. U.S. Geological Survey. Water-Resources Investigations Report 99-4259, p. 312.

Pérez-Garrido, C, Fernández-Díaz, L., Pina, C.M., Prieto, M., 2007. In situ AFM observations of the interaction between calcite $(1014)$ and $C d$ - bearing aqueous solutions. Surface Science 601, 5499-5509.

Pérez-Garrido, C. Astilleros, J.M., Fernández-Díaz, L., Prieto, M., 2009. In situ AFM study of the interaction between calcite $\{10 \overline{1} 4\}$ surface and supersaturated $\mathrm{Mn}^{2+}-\mathrm{CO}_{3}^{2-}$ aqueous solutions. Journal of Crystal Growth $311,4730-4739$.

Prieto, M., 2009. Thermodynamics and kinetics of water-rock interaction. Thermodynamics and Kinetics of Water-Rock Interaction: Reviews in Mineralogy \& Geochemistry, vol. 70, pp. 47-85.

Prieto, M., Astilleros, J.M., Pina, C.M., Fernández-Díaz, L., Putnis, A., 2007. Comment: supersaturation in binary solid solution-aqueous solution systems. American Journal of Science 307, 1034-1045.

Reddy, M., Nancollas, G.H., 1976. The crystallization of calcium carbonate. IV The effect of magnesium, strontium and sulfate ions. Journal of Crystal Growth 35, 33-38.

Reddy, M., Wang, K.K., 1980. Crystallization of calcium carbonate in the presence of metal ions. I. Inhibition by magnesium ion at $\mathrm{pH} 8.8$ and $25^{\circ} \mathrm{C}$. Journal of Crystal Growth 50, 470-480.

Rosenthal, Y., Boyle, E.A., Slowey, N., 1997. Temperature control on the incorporation of magnesium, strontium, fluorine, and cadmium into benthic foraminiferal shells from Little Bahama Bank: prospects for thermocline paleoceanography. Geochimica et Cosmochimica Acta 61, 3633-3643.

Sánchez Pastor, N., Pina, C.M., Fernández-Díaz, L., Astilleros,J.M., 2006. The effect of $\mathrm{CO}_{3}^{2-}$ on the growth of barite $\{001\}$ and $\{210\}$ surfaces: an AFM study. Surface Science 600 , $1369-1381$

Shtukenberg, A.G., Astilleros, J.M., Putnis, A., 2005. Nanoscale observations of epitaxial growth of hashemite on barite (001). Surface Science 590, 212-223.

Stanley, S.M., 1999. Earth System History. W. H, Freeman, New York. 615 pp.

Stanley, S.M., Hardie, LA., 1998. Secular oscillations in the carbonate mineralogy of reefbuilding and sediment-producing organisms driving by tectonically forced shifts in seawater chemistry. Palaeogeography, Palaeoclimatology, Palaeoecology 144,3-19.

Stephenson, A.E., DeYoreo, J.J., Wu, L, Wu, K.J., Hoyer, J., Dove, P.M., 2008. Peptides enhance magnesium signature in calcite: insights into origins of vital effects. Science 322, 724-727.

Teng, H.H., Dove, P.M., DeYoreo, J.J., 1999. Reversed calcite morphologies induced by microscopic growth kinetics: insight into biomineralization. Geochimica et Cosmochimica Acta 63, 2507-2512.

Tesoriero, A.J., Pankow,J.F., 1996. Solid solution partitioning ofSr ${ }^{2+}, \mathrm{Ba}^{2+}$, and $\mathrm{Cd}^{2+}$ to calcite. Geochimica et Cosmochimica Acta 60, 1053-1063.

van Enckevort, W.J.P., van den Berg, A.C.J.F., Kreuwel, K.B.G., Derksen, A.J., Couto, M.S. 1996. Impurity blocking of growth steps: experiments and theory. Journal of Crystal Growth 166, 156-161.

Vavouraki, A.I., Putnis, C.V., Putnis, A., Koutsoukos, P.G., 2008. An Atomic Force Microscopy study of the growth of calcite in the presence of sodium sulfate. Chemical Geology 253, 243-251.

Wasylenki, L.E., Dove, P.D., De Yoreo, J.J., 2005. Effects of temperature and transport conditions on calcite growth in the presence of $\mathrm{Mg}^{2+}$ : implications for paleothermometry. Geochimica et Cosmochimica Acta 69, 4227-7236. 